\title{
Percutaneous Mitral Valvotomy in Children and Adolescents: Immediate and Midterm Results
}

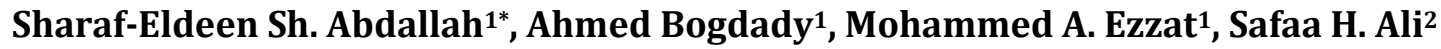 \\ ${ }^{1}$ Internal Medicine Department, Faculty of Medicine, Sohag University, Sohag, Egypt \\ ${ }^{2}$ Pediatric Department, Faculty of Medicine, Sohag University, Sohag, Egypt \\ Email: Sharaf003@gmail.com
}

Received 27 December 2014; accepted 1 April 2015; published 7 April 2015

Copyright (C) 2015 by authors and Scientific Research Publishing Inc.

This work is licensed under the Creative Commons Attribution International License (CC BY). http://creativecommons.org/licenses/by/4.0/

(c) (i) Open Access

\begin{abstract}
Objective: To analyze immediate and midterm results of percutaneous mitral valvotomy (PMV) in patients $\leq 18$ year, a single centre experience of Sohag university hospital. Methods: Between May 2010 and May 2012, 64 procedures of Inoue technique mitral valvotomy were performed on 64 patients. The mean age was $15.8 \pm 2.2$ years; $75 \%$ were females. Results: Success was obtained in $96.8 \%$ of patients. Immediate complications were severe mitral regurgitation $(3.1 \%)$, cardiac tamponade (1.6\%) and embolic stroke in (1.6\%). Late follow-up was obtained in $93.7 \%$ of the patients (at 6 and 24 months). Restenosis developed in 3 patients. Most of the patients had no symptoms at discharge but most of them had NYHA class I to II at 6 months to 2 years follow up. No patients died. Patients who operated early with MVA around 1.4 had best outcome. Conclusion: PMV represents a safe therapeutic option in young patients with mitral valve stenosis. In these patients, recurrence of symptoms and restenosis occurs at an earlier stage than in elderly. Earlier intervention carries better outcome and decreases restenosis rate.
\end{abstract}

\section{Keywords}

Inoue Technique Mitral Valvotomy, Restenosis, Children, Adolescents

\section{Introduction}

Mitral stenosis (MS) is almost invariably the result of chronic rheumatic heart disease secondary to one or more prior episodes of acute rheumatic fever especially in developing countries [1].

\footnotetext{
${ }^{*}$ Corresponding author.
}

How to cite this paper: Abdallah, S.-E.Sh., Bogdady, A., Ezzat, M.A. and Ali, S.H. (2015) Percutaneous Mitral Valvotomy in Children and Adolescents: Immediate and Midterm Results. World Journal of Cardiovascular Diseases, 5, 71-78. 
Since Inoue et al. introduced balloon mitral valvuloplasty BMV in 1984, this procedure has become the treatment of choice replacing surgical commissurotomy in most of cases [2]. Long-term outcome is favorable, with excellent survival rates without functional disability or need for repeat intervention [3] [4]. The results of BMV in those with adverse valve morphology and in young population are less predictable [5]-[8]. Percutaneous mitral valvotomy is now the first therapeutical choice for treating mitral stenosis in selected patients [9]. An appropriately sized balloon catheter for a safe stepwise dilation procedure is selected in order to avoid iatrogenic severe mitral regurgitation (MR) during BMV. Various criteria have been proposed for ideal balloon sizing, depending on the patient's height 10 body surface area (BSA), and mitral annulus size [10] [11]. The objective of this study was to describe early results and midterm clinical follow-up of PMV for treatment of rheumatic mitral stenosis in patients at younger age group than previous studies.

\section{Method}

The study was conducted on 68 patients prospectively with rheumatic mitral stenosis who are subjected to PMV using Inoue balloon technique during the period from May 2010 and May 2014 in one center (Sohag University Hospital, EGYPT).

Inclusion criteria included symptomatic MS with NYHA functional class II or more with mitral valve area (MVA) $\leq 1.5 \mathrm{~cm}^{2}$ and mitral valve Echocardiographic score $\leq 10$ according to scoring system described by Wilkins et al. [12] Exclusion criteria were patients with MR or aortic regurgitation (AR) of grade III/IV or more, also, patients with Wilkins scoring of $>10$ and presence of left atrial (LA) thrombi assessed by transesophageal echocardiography (TEE). Parameters were graded by at least two operators. All patients were subjected to full history taking and clinical examination, standard resting 12-lead electrocardiogram. Transthoracic TT and transesophageal TE echocardiographic and Doppler examinations were done just before intervention and one day after the procedure. Examination was acquired with a commercially available system (Vingmed Vivid S5, General Electric-Vingmed, Milwaukee, WI, USA) equipped with 2.5 and $3.5 \mathrm{MHz}$ transducers and $5 \mathrm{MHz}$ transesophageal monoplane transducer.

We studied mitral valve morphology using different scoring systems including Massachusetts General Hospital score by Wilkins et al. [12] We also measured mitral valve area (MVA), LA dimensions, transmitral maximum pressure gradient (MG), estimated systolic pulmonary artery pressure (SPAP), and presence of MR and its severity. Severity of MR(mitral regurgitation) was determined by expressing the ratio of maximal jet area to left atrial area in the same view using color flow mapping and graded from one to four according to Essop et al. [13] Severe MR was defined as the increase of $>2 / 4$ grades of MR.

Transesophageal echocardiography (TEE) was done the same day just before intervention for exclusion of LA and LA appendage thrombi, measuring of interatrial septal thickening, and reassessment of transthoracic echocardiographic data. Invasive hemodynamic study included predilatation and early postdilatation assessment of LA pressure and transmitral pressure gradient (PG). BMV using Inoue technique was done as described before in the literature [14].

\section{Statistical Analysis}

Data are presented as mean \pm SD. Categorial variables were compared using Student's t-test. Nonparametric data were compared using Chi-square tes. $\mathrm{p}$ value was considered significant when it was $<0.05$. Data were collected using SPSS version 15.

\section{Results}

Baseline characteristics of 64 patients are shown in (Table 1). The patients were aged $15.8 \pm 2.2$ years (range 12 18 years) with $75 \%$ of them females. $43 \%$ of the patients were NYHA functional class III or IV; symptomatic despite treatment with diuretic therapy, digoxin and $\beta$-blockers. All patients were not subjected to previous BMV. $29 \%$ of patients were in atrial fibrillation with a controlled ventricular rate.

The mean weight was $50.2 \pm 9.1 \mathrm{~kg}$ and mean height was $157.2 \pm 5.9 \mathrm{~cm}$. By TTE the mean mitral valve area was $1.225 \pm 0.24$, the mean mitral score was $7.37 \pm 1.06$ and the mean left atrial size was $4.28 \pm 0.5$. Mitral regurgitation in $22 \%$ of patients (grade I in $15.63 \%$ and grade II in $6.25 \%$ ).

Procedural data are collected in (Table 2). The hemodynamic mean diastolic gradient pre and post procedure 
Table 1. Patient characteristics and preoperative echocardiographic data.

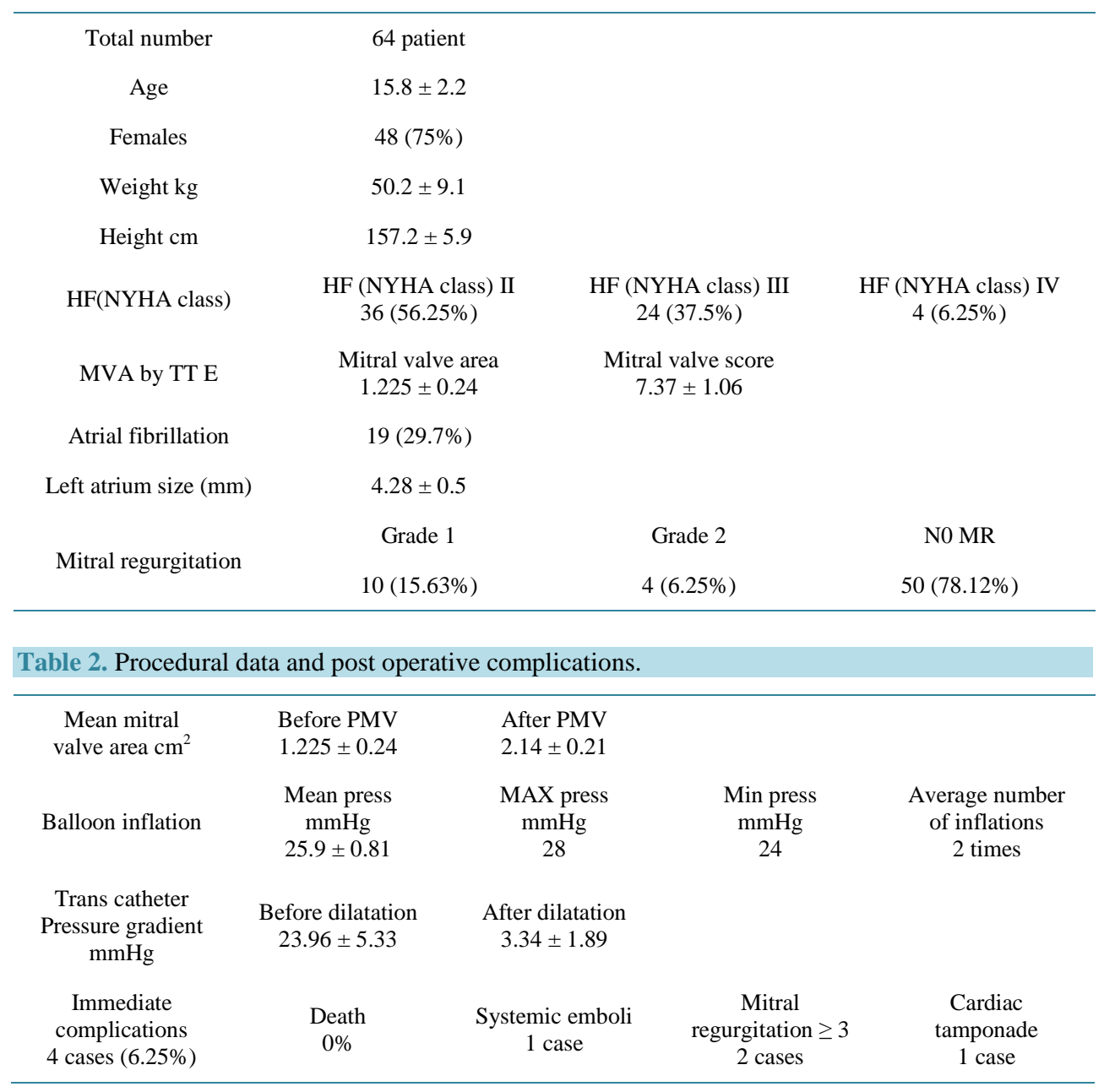

decreased from $23.96 \pm 5.33 \mathrm{mmHg}$ to $3.34 \pm 1.89 \mathrm{mmHg}(\mathrm{p}<0.001)$. Mean reduction in transcatheter pressure gradient across MV after procedure was $20.56 \pm 5.16 \mathrm{mmHg}$ but no significant correlation were detected between the level pressure gradient TC before dilatation and degree of reduction ( $P$ value 0.06 ) (Figure 1 ).

Average number of balloon inflations was 2 times ranged from one inflation to 3 successive inflations with upgrade increase in inflation pressure around $0.5 \mathrm{mmHg}$ each time. The procedure was considered successful in 62 (96.8\%) patients. The mean mitral valve area increased from $1.225 \pm 0.24 \mathrm{~cm}^{2}$ to $2.14 \pm 0.21 \mathrm{~cm}^{2}(\mathrm{p}<$ $0.0001)$.

Procedural complications are shown in (Table 2). Post BMV MR was absent in 40 patient, recorded as grade I in 20 patient, grade II in 2 patients, grade III in 1 patient and grade IV in 1 patient. Overall only 2 patients developed moderate to severe mitral regurgitation both of them had a tear of the anterior mitral leaflets. One of those two patients had MV score of 9 and preoperative MV regurgitation grade I and other with MV score of 8 and preoperative MV regurgitation grade II. The two patients had surgical mitral valve replacement. One AF patient had temporal left hemiparesis improved completely after 3 days (embolic stroke) and other survived cardiac tamponade after surgical intervention due to tear of free LA wall.

62 patients were followed up for 2 years. Average MVA immediately was $2.14 \mathrm{~cm}^{2}$, after 6 months was 1.89 $\mathrm{cm}^{2}$ and finally $1.82 \mathrm{~cm}^{2}$ after 2 years with significant reduction in MVA after 6 months (p value 0.03) and non significant reduction from 6 months to 2 years $(\mathrm{p}<0.06)$ (Figure 2). Restenosis was encountered in 3 patients.

Majority of the patients followed up showed an improvement in the functional class by at least 1 grade. ALL the patients had no symptoms of NYHA $\geq$ II at discharge and at 6 months but $18.75 \%$ developed NYHA class II at 2 years follow up (Figure 3). There were no late deaths. 


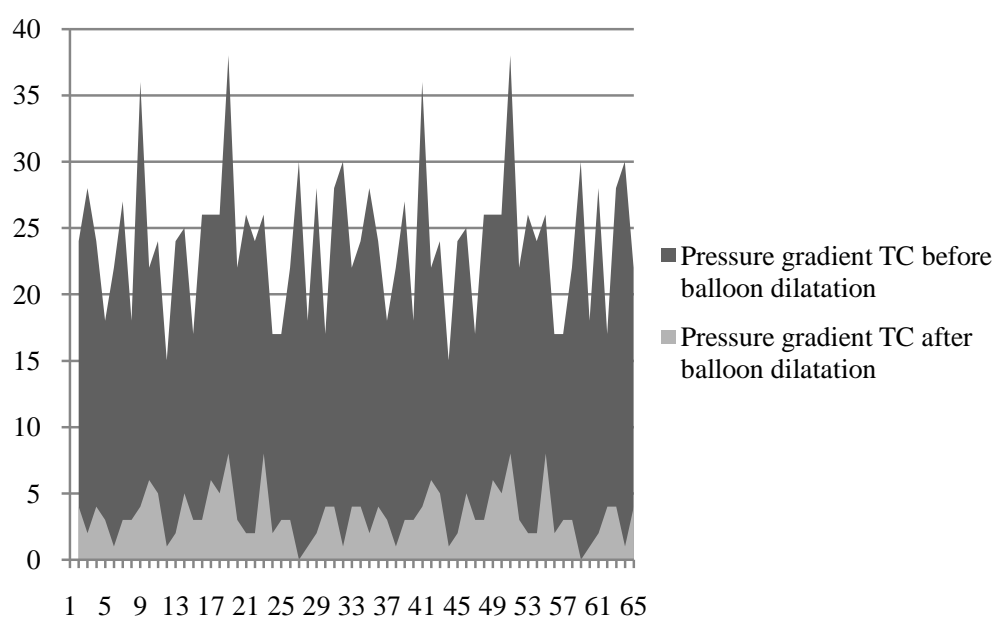

Figure 1. The hemodynamic mean diastolic gradient pre and post procedure (TC transcatheter).

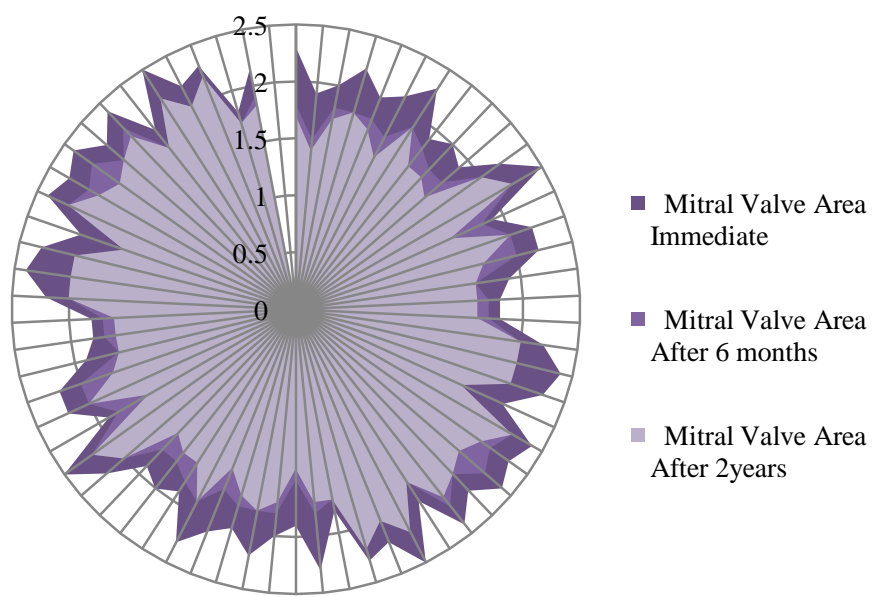

Figure 2. Follow up of mean mitral valve area MVA by TTE.

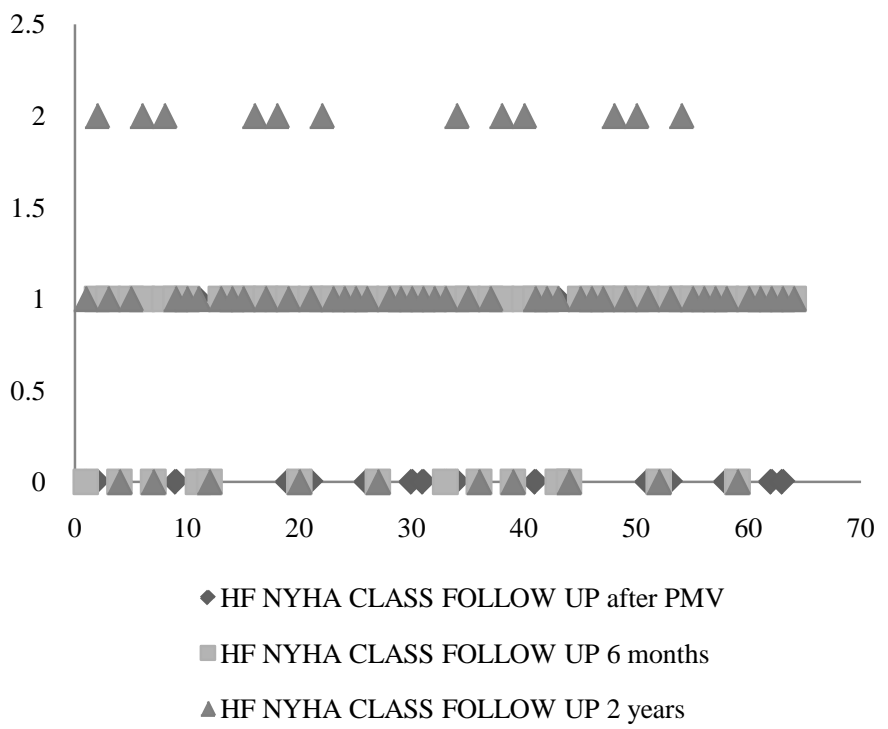

Figure 3. HF NYHA class follow up. 
Significant correlation between reduced NYHA class of HF after 2 years and initially relative wide MVA just before procedure $(\mathrm{p}<0.04)$ and Patients who operated early with MVA around 1.4 had best outcome. That's approved by significant correlation between 2 years TTE follow up of MVA with preoperative MVA $(\mathrm{P}<0.01)$.

There was no significant correlation between mitral valve score, mitral valve area immediately after PMV, transvalvular pressure gradient reduction and symptoms after 2 years $(\mathrm{P}<1.7,2.2$ and 1.1 respectively).

No significant correlation between 2 years follows up of MVA with mitral valve area immediately after PMV, transvalvular pressure gradient reduction and initial MV scoring $(\mathrm{P}<1.8,0.6$ and 0.07 respectively). Figure 4 showed that best NYHA class of HF after 2 year is for those who are operated early. Figure 5 and Figure 6 represents Transcatheter atrial septostomy and mitral valvotomy.

\section{Discussion}

Despite a dramatic fall in the incidence of rheumatic fever (RF), it continues to affect young people [11]. Balloon mitral valvotomy (BMV) was first performed in 1982 by Kanji Inoue [2] in Japan. Balloon mitral valvuloplasty gives an excellent result and is equal to that obtained with open or closed surgical valvotomy and benefit is sustained during long term follow up [15]. The results of this study show that BMV is a safe and effective procedure for symptomatic mitral stenosis in young population with low rate of complication and smooth outcome after 2 years. This study demonstrates that BMV results in a good immediate hemodynamic and clinical improvement in the majority of patients (96.8\%) with mitral stenosis which is similar to other studies [15]-[17]. In-hospital complications were low with no deaths. Data reporting the immediate results obtained in this group of patients do not differ significantly from those observed in the general population undergoing this type of procedure [10].

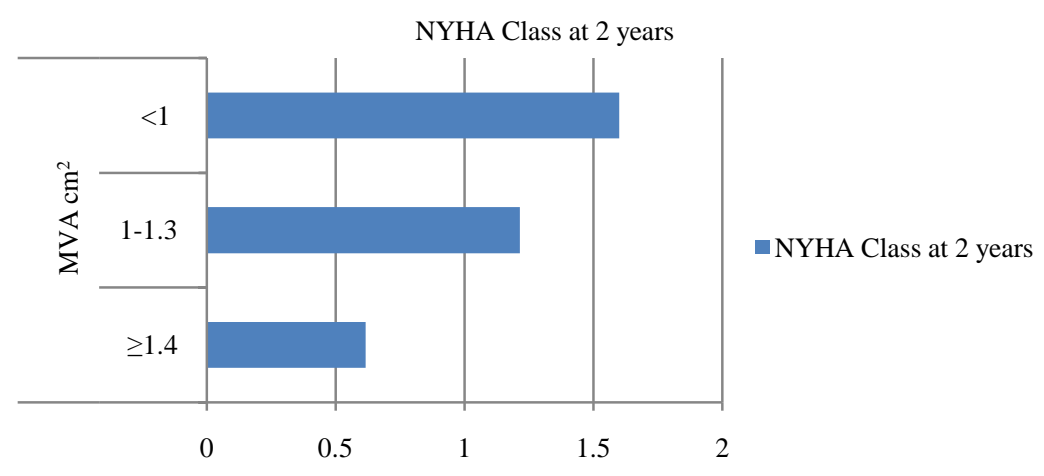

Figure 4. Relation between NYHA class of HF after 2 years and MVA just before procedure.

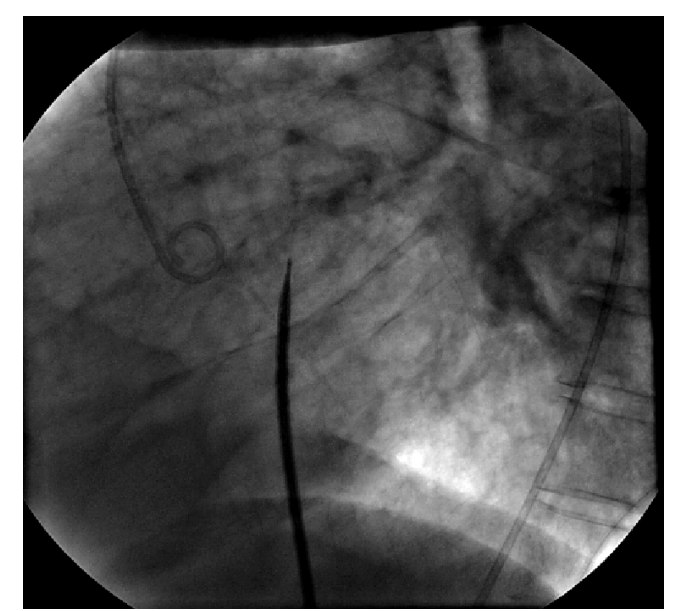

Figure 5. Transcatheter atrial septostomy and LA delineation with contrast (pigtail catheter in aorta to avoid aortic injury). 


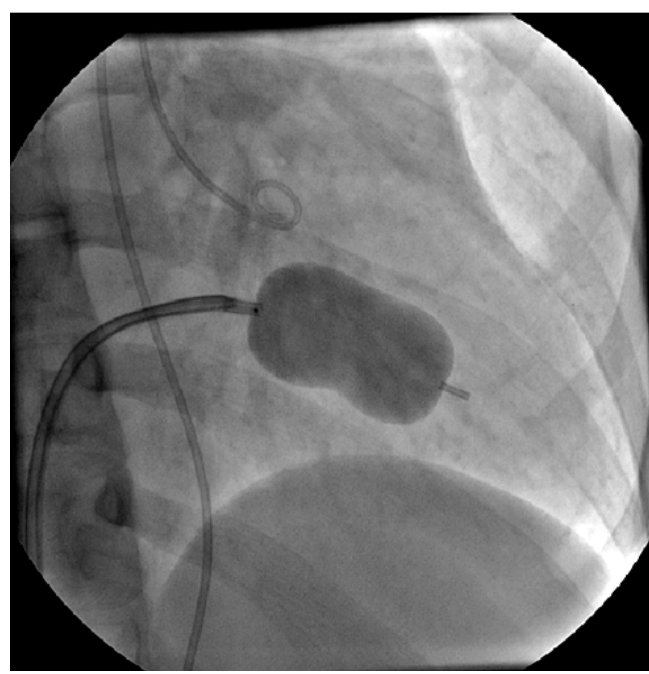

Figure 6. Mitral valvotomy using Inoue balloon.

Reduction of MVA and of the mean diastolic transmitral gradient with symptomatic relief confirmed the efficacy of this technique.

The incidence of mitral regurgitation (37.5\%) is slightly higher than observed in the general population (29.2\%) [10]. Only 2 patients had MR > grade II/IV necessities surgical intervention. As is well known, the main predictors of this complication are oversizing of the balloon [18], commissural or leaflet calcification or both and the intensity of the involvement of the mitral subvalvar apparatus [19] [20]. In our study one had high score and the other had already MR of grade II before intervention.

The restenosis incidence in our study was $4.8 \%$ patients at 2 years follow up as the majority of patients were having an echocardiographic score of around 7 to 8 which may be similar to other studies with longer follow up periods and older age groups. An incidence ranging from 6.5\% to 40\% [15] [21]-[23] Chen et al., [15] reported an 11 year incidence of 8\%. Zaki et al. [21], from Egypt reported 5 year restenosis rate of 6.5\%. Fawzy et al. [22], from Saudi Arabia have reported 5 year restenosis incidence of $14.3 \%$ and $16.1 \%$ in patients less than and more than 20 years respectively. They have again reported 31\% restenosis rate in 531 patients with mean follow-up of 8.5 years [23]. Hernandez et al. [3], from Spain have reported a restenosis rate of $39 \%$ at 7 years. Wang et al. [24], reported $40 \%$ restenosis rate at 6 years follow up and this was predicted by higher echocardiographic score.

Valve morphology was not the main determinant of restenosis in our study but initial MVA. In which earlier intervention for patients with MVA $\geq 1.4 \mathrm{~cm}^{2}$ had better outcome and best results of follow up for MVA and symptoms.

Reduction of mitral valve area was more significant early at first 6 months which might abolish the understanding of that the main mechanism of restenosis in young adults due to recurrent subclinical rheumatic attacks, which usually cannot be detected clinically or by laboratory tests. Based on these results and considering the problem imposed by future re-interventions, we believe that percutaneous treatment should be the primary intervention, because its immediate and late results are similar to those obtained by surgery $4-6$, which has a higher morbidity. Another advantage of the percutaneous procedure is that redilations can be performed without technical difficulties in the additional procedures and without a higher incidence of complications.

It is well known that rheumatic disease has a chronic and progressive course and young patients are prone to undergoing more than one valvular procedure during their lifetime. Therefore, when this becomes necessary, surgery can be performed without the inherent risks of a previous thoracotomy.

\section{Conclusion}

PMV represents a safe therapeutic option in young patients with mitral valve stenosis. In those patients, recurrence of symptoms and restenosis occurs at an earlier stage than in elderly. Earlier intervention carries better outcome and decreases restenosis rate. 


\section{References}

[1] Wood, P. (1954) An Appreciation of Mitral Stenosis: II. Investigations and Results. British Medical Journal, 1, 11131124. http://dx.doi.org/10.1136/bmj.1.4871.1113

[2] Inoue, K., Owaki, T. and Nakamura, T. (1984) Clinical Application of Transvenous Mitral Commissurotomy by a New Balloon Catheter. Journal of Thoracic and Cardiovascular Surgery, 87, 394-402.

[3] Hernandez, R., Banuelos, C., Alfonso, F., et al. (1999) Long-Term Clinical and Echocardiographic Follow-Up after Percutaneous Mitral Valvuloplasty with the Inoue Balloon. Circulation, 99, 1580-1586. http://dx.doi.org/10.1161/01.CIR.99.12.1580

[4] Lung, B., Gardarz, E., Michaud, P., et al. (1999) Late Results of Percutaneous Mitral Commissurotomy in a Series of 1024 Patients. Analysis of the Late Clinical Deterioration: Frequency, Anatomic Findings, and Predictive Factors. Circulation, 99, 3272-3278.

[5] Yoshida, Y., Kubo, S., Tamaki, S., et al. (1995) Percutaneous Transvenous Mitral Commissurotomy for Mitral Stenosis Patients with Markedly Severe Mitral Valve Deformity: Immediate Results and Long-Term Clinical Outcome. American Journal of Cardiology, 76, 406-408. http://dx.doi.org/10.1016/S0002-9149(99)80113-1

[6] Dean, L.S., Mickel, M., Bonan, R., et al. (1996) Four-Year Follow-Up of Patients Undergoing Percutaneous Balloon mitral Commissurotomy. Journal of the American College of Cardiology, 28, 1452-1457. http://dx.doi.org/10.1016/S0735-1097(96)00350-6

[7] Hung, J.S. and Lau, K.W. (1999) Percutaneous Transvenous Mitral Commissurotomy Is an Acceptable Therapeutic Alternative in Patients with Calcified Mitral Valve. Journal of Invasive Cardiology, 11, 362-363.

[8] Wahl, A. and Meier, B. (1999) Percutaneous Mitral Balloon Valvuloplasty in Nonideal Patients: Go for It without Expecting Too Much. Journal of Invasive Cardiology, 33, 120-129.

[9] Feldman, T. (1994) Hemodynamic Results, Clinical Outcomes and Complications of Inoue Balloon Mitral Valvotomy. Catheterization and Cardiovascular Diagnosis, 2, 2-7.

[10] Radhakrishnan, S. and Shrivastava, S. (1993) Balloon Mitral Valvotomy: Our Perspective. Journal of Postgraduate Medicine, 39, 49-50.

[11] Sanati, H.R., Kiavar, M., Salehi, N., Shakeria, F., et al. (2010) Percutaneous Mitral Valvuloplasty—A New Method for Balloon Sizing Based on Maximal Commissural Diameter to Improve Procedural Results. The American Heart Hospital Journal, 8, 29-32.

[12] Wilkins, G.T., Weyman, A.E., Abascal, V.M., Block, P.C. and Palacios, I.F. (1988) Percutaneous Balloon Dilatation of the Mitral Valve: An Analysis of Echocardiographic Variables Related to Outcome and the Mechanism of Dilatation. British Heart Journal, 60, 299-308. http://dx.doi.org/10.1136/hrt.60.4.299

[13] Essop, M.R., Wisenbaugh, T., Skoularigis, J., Middlemost, S. and Sareli, P. (1991) Mitral Regurgitation Following Mitral Balloon Valvotomy. Differing Mechanisms for Severe versus Mild-Tomoderate Lesions. Circulation, 84, 16691679. http://dx.doi.org/10.1161/01.CIR.84.4.1669

[14] Inoue, K. and Hung, J.S. (1990) Percutaneous Transvenous mitral Commissurotomy (PTMC). The Far East Experience. In: Topol, E.J., Ed., Text Book of Interventional Cardiology, W.B. Saunders, Philadelphia, 887-899.

[15] Chen, C.R., Cheng, T.O., Chen, J.Y., et al. (1998) Long-Term Results of Percutaneous Balloon Mitral Valvuloplasty for Mitral Stenosis: A Follow-Up Study to 11 Years in 202 Patients. Catheterization and Cardiovascular Diagnosis, 43, 132-139. http://dx.doi.org/10.1002/(SICI)1097-0304(199802)43:2<132::AID-CCD5>3.0.CO;2-B

[16] Arora, R., Nair, M., Kalra, G.S., Nigam, M. and Khalilullah, M. (1993) Immediate and Long-Term Results of Balloon and Surgical Closed Mitral Valvotomy: A Randomized Comparative Study. American Heart Journal, 125, 1091-1094. http://dx.doi.org/10.1016/0002-8703(93)90118-S

[17] Fawzy, M.E., Mimesh, L., Sivanandam, V., Lingamanaicker, J., Al-Amiri, M., Khan, B., et al. (1996) Advantage of Inoue Balloon Catheter in Mitral Balloon Valvotomy: Experience with 220 Consecutive Patients. Catheterization and Cardiovascular Diagnosis, 38, 9-14. http://dx.doi.org/10.1002/(SICI)1097-0304(199605)38:1<9::AID-CCD3>3.0.CO;2-E

[18] Padial, L.R., Abascal, V.M., Moreno, P.R., Weyman, A.E., Levine, R.A. and Palacios, I.F. (1999) Echocardiography Can Predict the Development of Severe Mitral Regurgitation after Percutaneous Mitral Valvuloplasty by the Inoue Technique. American Journal of Cardiology, 83, 1210-1213. http://dx.doi.org/10.1016/S0002-9149(99)00061-2

[19] Sutaria, N., Northridge, D.B. and Shaw, T.R.D. (2000) Significance of Commissural Calcification on Outcome of Mitral Balloon Valvotomy. Heart, 84, 398-402. http://dx.doi.org/10.1136/heart.84.4.398

[20] Elasfar, A.A. and Elsokkary, H.F. (2011) Predictors of Developing Significant Mitral Regurgitation Following Percutaneous Mitral Commissurotomy with Inoue Balloon Technique. Cardiology Research and Practice, 2011, Article ID: 703515. http://dx.doi.org/10.4061/2011/703515 
[21] Zaki, A., Salama, M., El Masry, M., et al. (1999) Five-Year Follow-Up after Percutaneous Balloon Mitral Valvuloplasty in Children and Adolescents. The American Journal of Cardiology, 83, 735-739. http://dx.doi.org/10.1016/S0002-9149(98)00980-1

[22] Fawzy, M.E., Stefadouros, M.A., Hegazy, H., et al. (2005) Long Term Clinical and Echocardiographic Results of Mitral Balloon Valvotomy in Children and Adolescents. Heart, 91, 743-748. http://dx.doi.org/10.1136/hrt.2004.040766

[23] Fawzy, M.E., Shoukri, M., Shaer, F.E., et al. (2007) 18 Years Follow-Up Results of Mitral Balloon Valvuloplasty in 531 Consecutive Patients and Predictors of Long-Term Outcome. Heart Views, 8, 130-141.

[24] Wang, A., Krasuski, R.A. and Warner, J.J. (2002) Serial Echocardiographic Evaluation of Restenosis after Successful percutaneous Mitral Commissurotomy. Journal of the American College of Cardiology, 39, 328-334. http://dx.doi.org/10.1016/S0735-1097(01)01726-0 